\title{
Análise dos fatores de influência e diagnóstico da gestão dos resíduos da construção civil (RCC) nos canteiros de obra da cidade do Recife-PE
}

Analysis of the factors of influence and diagnosis of the management of the residues of the civil construction (RCC) in the construction sites of the city of Recife-PE

Cidney Ribeiro Vieiral ${ }^{[a]}$, Joaquin Humberto Aquino Rocha ${ }^{[b]}$ [D,

Kalinny Patrícia Vaz Lafayette ${ }^{[a], ~ D e ́ b o r a ~ M a r i a ~ d a ~ S i l v a l a] ~}$

[a] Universidade de Pernambuco (UPE), Escola Politécnica de Pernambuco, Programa de Pós-graduação em Engenharia Civil, Recife, PE, Brasil

[b] Universidad Privada del Valle (UNIVALLE), Facultad de Tecnologia, Departamento de Ingeniería Civil, Cochabamba, Bolívia

Como citar: Vieira, C. R., Rocha, J. H. A., Lafayette, K. P. V., \& Silva, D. M. (2019). Análise dos fatores de influência e diagnóstico da gestão dos resíduos da construção civil (RCC) nos canteiros de obra da cidade do Recife-PE. urbe. Revista Brasileira de Gestão Urbana, v.11, e20180176. https://doi.org/10.1590/2175-3369.011.e20180176

\section{Resumo}

O objetivo deste artigo consiste em identificar os fatores de maior influência da geração dos RCC, assim como diagnosticar a gestão dos resíduos nos canteiros de obras da cidade de Recife-PE. A identificação dos fatores de influência se deu através do levantamento de informações por meio de entrevistas e aplicação de questionários com os responsáveis de 35 obras. Em 15 obras foi realizado um diagnóstico da gestão dos resíduos, identificando fisicamente os métodos utilizados para gerenciar os fluxos gerados. Os fatores influenciadores indicaram como principais aspectos relacionados à geração dos RCC, o sobreconsumo de materiais, complexidade e alteração nos projetos, além dos processos construtivos envolvidos. 0 diagnóstico realizado da gestão dos RCC mostrou que 15 obras não tinham dados completos de geração de resíduos; 8 obras possuíam certificação ISO 14001, sendo que estas tinham uma forma mais eficaz de gestão dos RCC em relação as que não eram certificadas. Os resultados permitem observar que existe desconhecimento sobre o consumo dos materiais e produção de resíduos dentro dos canteiros. Uma adequada avaliação permitirá um melhor desempenho destas empresas, não apenas no aspecto ambiental, mas também na sobrevivência das mesmas empresas, criando empreendimentos de sucesso.

Palavras-chave: Desperdício de materiais. Geração de RCC. Processos construtivos.

\section{Abstract}

This article aims to identify the factors of influence of the RCC generation, as well as to diagnose waste management at construction sites in the city of Recife-PE. The identification of the factors of influence occurred through the collection of information through interviews and the application of questionnaires with those responsible for 35 construction sites. In 15 construction sites, a diagnosis of waste management was carried

CRV é Engenheiro civil, Mestre em Engenharia Civil, e-mail: crv_pec@poli.br

JHAR é Engenheiro civil, Mestre em Engenharia Civil, e-mail: joaquinaquinorocha@gmail.com

KPVL é Engenheira civil, Doutora em Engenharia Civil, e-mail: klafayette@poli.br

DMS é licenciada em Geografia, e-mail: debora.geografiaufpe@gmail.com 
out, physically identifying the methods used to manage the generated waste streams. The influencing factors indicated as main aspects related to the RCC generation, the overconsumption of materials, complexity and alteration in the projects, besides the constructive processes involved. The diagnosis made on the management of RCC showed that 15 construction sites did not have complete waste generation data; 8 construction sites had ISO 14001 certification, and these had a more effective way of managing RCCs to those that were not certified. There is a lack of knowledge about the consumption of materials and the production of waste inside the construction sites. An adequate evaluation will allow a better performance of these companies, not only in the environmental aspect but also in the survival of the same companies, creating successful ventures.

Keywords: Waste of materials. RCC generation. Constructive processes.

\section{Introdução}

A indústria da construção civil exerce uma forte influência no desenvolvimento econômico de uma nação. O Brasil, devido ao rápido processo de urbanização e crescimento do setor da indústria da construção, tem presenciado um elevado índice de geração de resíduos, conhecidos como resíduos da construção civil (RCC), que causam diversos impactos ao meio ambiente quando são dispostos de maneira inadequada, afetando a qualidade de vida e a saúde pública (Costa et al., 2014; Fernandes \& Silva Filho, 2017; Magalhães et al., 2017; Wu et al., 2017). Apesar dos valores registrados dos RCC, acredita-se que sejam maiores do que tem registro, devido sobretudo à falta de dados disponíveis sobre a quantidade real de resíduos gerados (Paz, 2014).

Como a indústria da construção é um grande consumidor de recursos naturais (Bohnenberger et al., 2018), a enorme quantidade de resíduos de construção aponta para uma maior necessidade de reaproveitamento e diminuição em termos de geração (Li-Yashuai, 2013), sendo que estudos recentes demonstram que os resíduos da construção civil têm um elevado potencial de reciclagem (Mália et al., 2013; Melo et al., 2013; Marques et al., 2013; Paz \& Lafayette, 2016).

0 surgimento de leis específicas para o setor vem mobilizando tanto empresas privadas quanto administradores públicos para o correto manejo dos RCC (Silva et al., 2018). Neste sentido, surge a Resolução do 307/2002 do CONAMA, que classifica os RCC em quatro categorias distintas (A, B, C e D), conforme ao tipo de material e da forma de destinação que deverá ser dada ao resíduo gerado (CONAMA, 2002). Os RCC classificados como Classe A são definidos como materiais de baixa periculosidade, pouco poluentes, podendo ser encontrados nas demolições de casas, reformas, construção de estradas e edifícios, nas escavações de fundações e preparo das obras, sejam elas de caráter público ou privado. Este tipo de resíduo é também conhecido pela sua deposição irregular nos centros urbanos (Monteiro, 2012).

Entretanto, na capital Pernambucana como outras cidades brasileiras, diversos pontos de descarte irregular dos resíduos da construção, muitos desses pontos localizados próximos a canteiros de obras, margens de rio, bordas de canais, pistas e acostamentos, trazendo diversos problemas para a cidade (Albuquerque, 2015; Santos, 2015; Paz \& Lafayette, 2016). Considerando também que estas deposições são cada vez maiores em número e quantidade de material.

Nesse contexto, o objetivo do artigo é determinar os principais fatores que influenciam a geração de RCC, diagnosticar a gestão de resíduos da construção civil nos canteiros de obra da cidade do Recife-PE, e propor algumas ações para que as empresas construtoras possam evitar esse elevado índice de desperdício identificado nas obras, de modo que possam gerar receitas, diminuir as suas despesas, além de reduzir os impactos ambientais.

\section{Desperdício de materiais na construção civil}

De acordo com a Câmara Brasileira da Indústria da Construção (CBIC), o setor responde por cerca de 50\% dos investimentos nacionais, sendo esta a maior parcela dos recursos econômicos destinados ao financiamento de novos empreendimentos, sejam estes investimentos privados ou públicos (CBIC, 2019). É responsável ainda pelo elevado consumo de matérias primas, em torno de $50 \%$ de todos os recursos naturais que são consumidos pela população (Mesquita, 2012). 
Esses valores apontam o quanto a indústria da construção civil é importante para a economia brasileira. Contudo, apesar de números bastante significativos, Mendoza, Altabella \& Izquierdo (2016), destacam que uma pequena parcela do desperdício e resíduos gerados é reaproveitada, e que a construção civil pela enorme quantidade de matérias-primas que são consumidas e não são recicladas, tornou-se uma atividade econômica não sustentável.

As perdas que acontecem no decorrer do processo construtivo não podem ser consideradas desprezíveis e diante de um mercado competitivo, onde os consumidores são exigentes quanto à qualidade do produto, as empresas têm que, obrigatoriamente, reduzir seus custos de produção, diminuindo os desperdícios, melhorando e aproveitando todos os recursos disponíveis (Pinho, 2013).

Estudos realizados em vários países constataram que as perdas representam um percentual relativamente elevado nos custos da construção, devendo, portanto, ser tema de discussão objetivando a sua redução (Viana et al., 2012). A ocorrência das perdas pode acontecer em diferentes fases dos empreendimentos: concepção, execução e utilização; e cada fase com um conceito de perda diferente. Como são explorados os resíduos gerados nos canteiros de obras da Cidade de Recife, o conceito a ser usado corresponde a fase de execução, onde perda é definida pela diferença entre a quantidade prevista no projeto idealizado e a quantidade efetivamente consumida (Souza et al., 1998).

Na fase de execução, segundo Santos \& Santos (2017), existem diversos tipos de perdas, dentre elas se destacam: o improviso que ocorre normalmente quando uma atividade se inicia sem que todos os recursos estejam disponíveis ou em quantidade necessária; a falta de terminalidade, quando se mobiliza um recurso para realizar uma tarefa e tira-se esse recurso sem que a atividade tenha sido terminada; e o retrabalho, oriundo de mão de obra não qualificada, inobservância de projetos, ou sequenciamento incorreto das atividades.

De acordo com Pinho (2013), os fatores que causam os desperdícios na construção civil estão associados a três categorias: variação do projeto, seleção dos materiais e métodos construtivos. Assim, é bastante comum acontecer solicitações de clientes para mudança no projeto, ocasionando retrabalhos e desperdícios. 0 custo é o principal critério de escolha para seleção de materiais e métodos construtivos, não considerando, portanto, aquele que seja mais racional e que gere menos resíduos.

\section{Caracterização da área do estudo}

O estudo foi realizado na cidade do Recife, capital do estado de Pernambuco, estando situado na região Nordeste do Brasil, abrangendo uma extensão territorial de $218,435 \mathrm{~km}^{2}$, altitude em relação ao nível do mar de quatro metros, com clima predominante quente e úmido com temperaturas médias anuais em torno de $25,8{ }^{\circ} \mathrm{C}$ (IBGE, 2017a).

O Recife limita-se ao norte pelas cidades de Paulista e Olinda, a leste pelo oceano Atlântico, ao sul pela cidade de Jaboatão dos Guararapes e a oeste pelos municípios de Camaragibe e São Lourenço da Mata (Figura 1). 0 município ocupa uma posição central e de destaque no nordeste do Brasil, situado a $800 \mathrm{~km}$ das metrópoles de Salvador e Fortaleza e a cerca de $300 \mathrm{~km}$ de Natal (IBGE, 2017a).

Segundo dados do IBGE (2017b), a cidade do Recife tem uma população estimada de 1.633 .697 habitantes, conta ainda com 541.854 domicílios, sendo o município mais populoso do estado com uma densidade demográfica de 7.039,64 hab $/ \mathrm{km}^{2}$. A cidade está dividida em 6 Regiões Político Administrativas (RPA): RPA 1-Centro; RPA 2-Norte; RPA 3-Noroeste; RPA 4-Oeste; RPA 5-Sudoeste e RPA 6-Sul (Recife, 1997), como apresentado na Figura 2. 


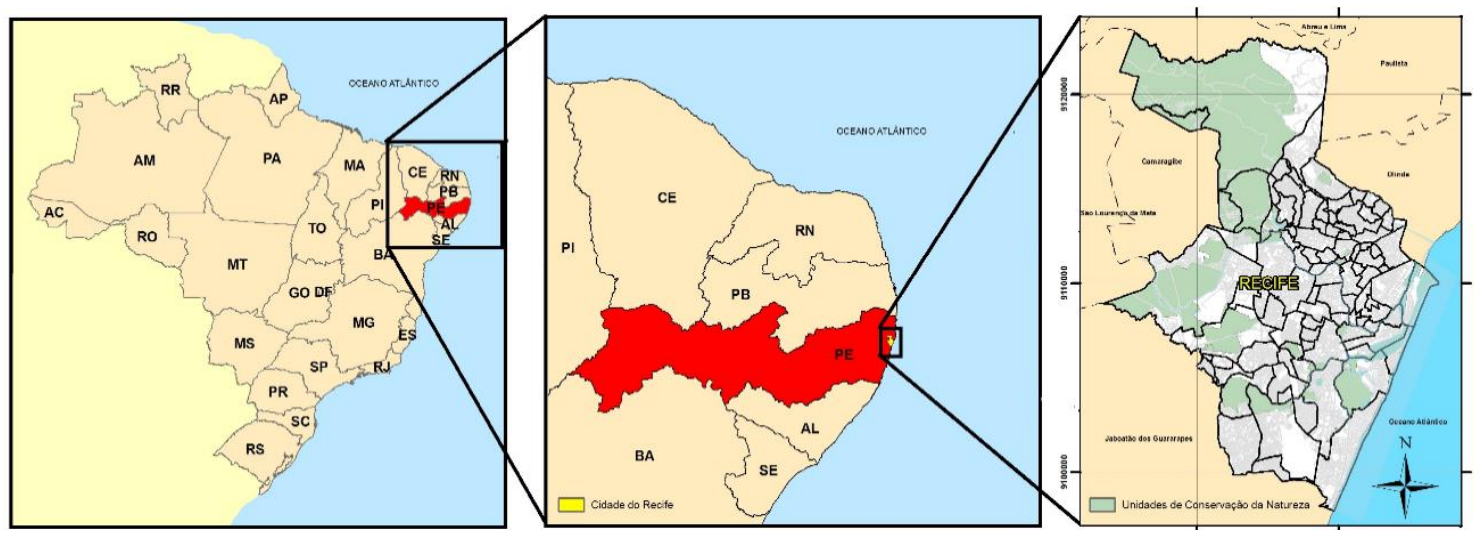

FIGURA 1 - Localização do município de Recife - PE. Fonte: Autores (2018).

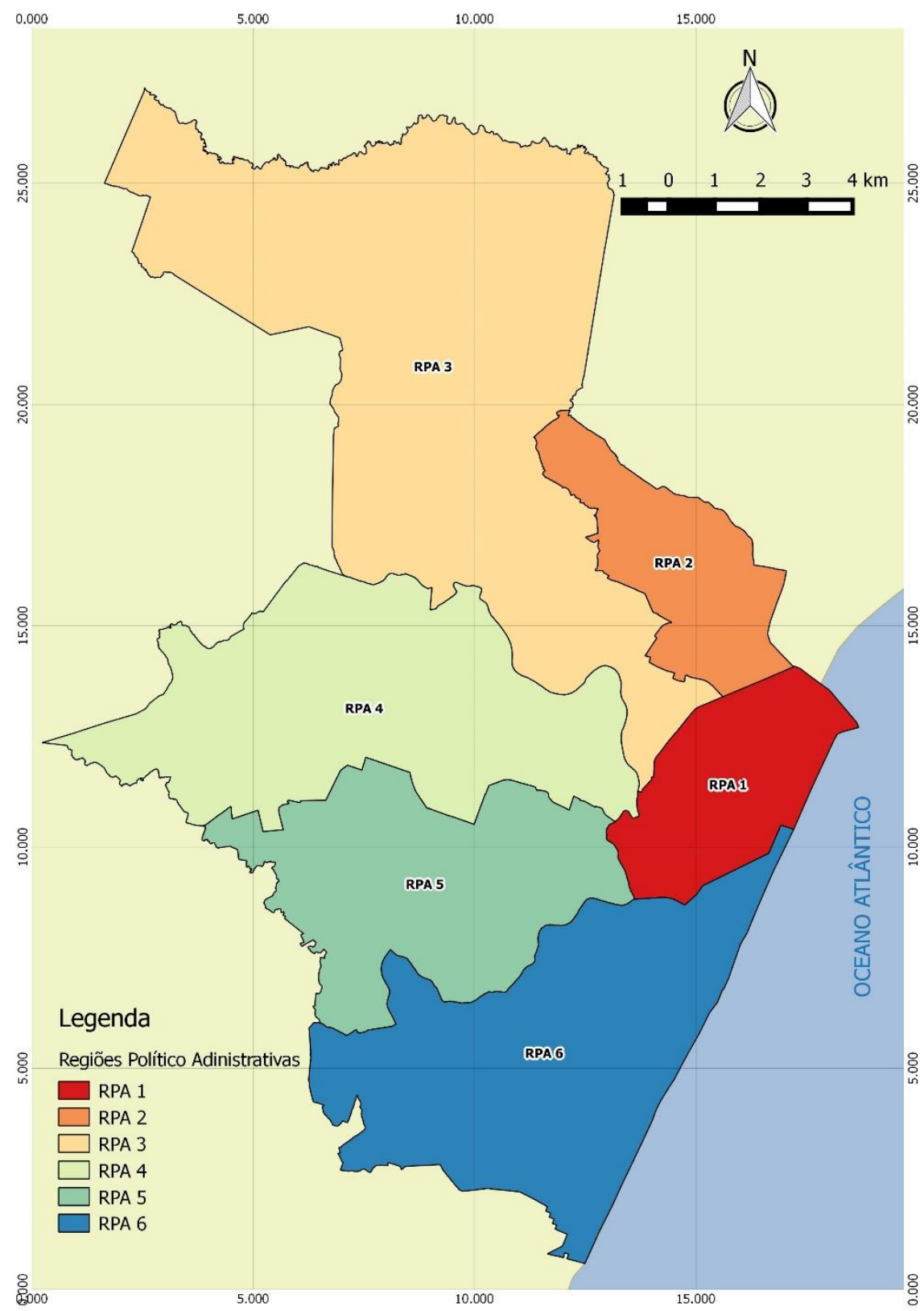

FIGURA 2 - Localização das RPA's na cidade do Recife - PE. Fonte: Autores (2018). 


\section{Metodologia}

O método realizado foi do tipo explicativo, com elementos descritivos de abordagem quali-quantitativa. A abordagem qualitativa foi feita a partir de um levantamento de informações através de entrevistas e aplicação de questionários com os responsáveis e pessoal das obras estudadas, de modo que se pôde explorar mais amplamente o objeto em estudo. A abordagem quantitativa se deu a partir da atribuição de valores em uma escala de um a cinco para avaliação das respostas dos entrevistados, dadas a todos os itens.

\section{Definição do tamanho da amostra}

Foi realizada inicialmente uma análise estatística, a fim de determinar a quantidade necessária de obras a serem analisadas. Verificou-se, com a Prefeitura da cidade do Recife (PCR), dados de todas as obras licenciadas de janeiro de 2014 a dezembro de 2016, período de início da construção de todos os empreendimentos monitorados.

Neste intervalo de tempo, foram cadastrados 357 processos de licenciamento para emissão de alvará de construção emitido pela Prefeitura do Recife (PCR). Em 2014 (148 obras), em 2015 (118 obras) e em 2016 (91 obras), totalizando os 357 processos cadastrados no período.

Uma amostra não probabilística de 35 obras em estágio de construção foi definida, pela acessibilidade dos dados. A escolha foi realizada por conveniência, com a premissa de serem obras situadas na cidade do Recife - PE, executadas por diferentes construtoras, levando-se em consideração os seguintes critérios: certificadas ou não; múltiplos pavimentos; fase de execução (fundação, estrutura ou acabamento); porte da empresa (pequeno, médio ou grande porte). Foram cadastradas obras de sete construtoras de pequeno, médio e grande porte, com elevada representatividade no mercado imobiliário local e tempo de atuação entre 20 e 40 anos.

\section{Coleta de dados}

Do levantamento, verificou-se que das 35 obras selecionadas, 21 iniciaram em 2014, oito em 2015 e seis em 2016. Os fatores de influência da geração dos resíduos foram analisados nas 35 obras. Em 15 obras realizou-se um diagnóstico para avaliar as ferramentas de gestão ambiental, uma vez que foi possível ter um contato direto com o processo de gerenciamento de resíduos. As informações foram obtidas através da aplicação de um questionário semi-estruturado, entrevistas pessoais e visitas periódicas, consultando aos gestores e pessoal da obra. 0 questionário foi elaborado com o objetivo de coletar informações gerais das obras e o perfil dos gestores, a fim de identificar experiências relativas à gestão dos RCC.

O questionário aplicado possibilitou, ainda, coletar informações intrínsecas aos processos construtivos das obras, descrevê-las de modo a obter os tipos de fundação e estruturas adotadas e as principais técnicas construtivas empregadas, e analisar a sua influência em uma menor ou maior geração de RCC, sendo possível também realizar um diagnóstico da gestão dos resíduos nos canteiros das obras.

\section{Técnicas e fontes de análise}

Para avaliação dos fatores de influência nas 35 obras, os dados obtidos foram analisados com o uso de métodos estatísticos descritivos e inferenciais, utilizando a metodologia de análise proposta por Wahab \& Lawal (2011). 0 método do índice de importância relativa (IIR) foi utilizado para mostrar o nível dos fatores, que contribuem para a geração dos resíduos nos canteiros de obras. 0 IIR foi calculado para cada fator de influência, a partir da análise da classificação indicado pelos entrevistados com a utilização da escala de Likert.

A escala de Likert é a soma das respostas dadas a cada item obtido dos entrevistados. 0 que se deseja medir é o nível de concordância ou discordância em relação a uma afirmação, sendo utilizados cinco níveis de respostas. A escala atribui a seguinte pontuação para estes níveis: cinco - muitíssimo relevante (MIR), quatro muito relevante (MR), três - relevante (R), dois - pouco relevante (PR) e um - não relevante (NR). 
O IIR é a razão entre a "soma do valor de peso" (SVP) e o número total de respondentes as perguntas a partir de todas as classificações ( $\Sigma \mathrm{x}_{\mathbf{i}}$ ), representada pela Equação 1 (Wahab \& Lawal, 2011). Quanto mais próximo IIR a cinco, maior é o grau de importância dos fatores de influência categorizados e listados. O SVP é a adição do produto do valor associado de cada classificação e respectivo número de entrevistados de acordo com a Equação 2, proposta por Wahab \& Lawal (2011).

$\mathrm{IIR}=\mathrm{SVP} / \Sigma_{\mathrm{xi}}$

$\mathrm{SVP}=\Sigma_{\mathrm{xiyi}}$

Onde:

xi = Número de resposta a cada classificação "ij”, onde "j” é a quantidade de respostas obtidas para determinada classificação.

yi $=0$ valor de classificação de i, onde i varia de um a cinco.

No caso do diagnóstico das 15 obras, foi utilizada uma análise qualitativa, para avaliar as ferramentas de gestão ambiental, quanto ao tipo triagem ou segregação na fonte, modo de acondicionamento, meios de transporte internos e externos e a forma de destinação final dos RCC. Esse diagnóstico rendeu um acervo fotográfico das obras em suas diversas fases e permitiu analisar as obras que possuíam melhores ferramentas de gestão.

\section{Análise e discussão dos resultados}

\section{Perfis da administração das obras}

A Tabela 1 indica o perfil dos funcionários dessas obras, a proporção de administrador por obra, rotatividade, tempo de experiência e o padrão construtivo dessas obras.

\begin{tabular}{|c|c|c|}
\hline Perfil dos funcionários & Frequência & Porcentagem \\
\hline \multicolumn{3}{|l|}{ Descrição das funções } \\
\hline Engenheiro Civil & 15 & 71,43 \\
\hline Arquiteto & 3 & 14,29 \\
\hline Técnico em Edificações & 2 & 9,52 \\
\hline Auxiliar de Engenharia & 1 & 4,76 \\
\hline Total & 21 & 100,0 \\
\hline \multicolumn{3}{|c|}{ Proporção de administrador por obra } \\
\hline $1 / 1$ & 12 & 57,14 \\
\hline $1 / 2$ & 5 & 23,81 \\
\hline $1 / 3$ & 3 & 14,29 \\
\hline $1 / 4$ & 1 & 4,76 \\
\hline Total & 21 & 100,00 \\
\hline \multicolumn{3}{|l|}{ Rotatividade da administração } \\
\hline 0 & 10 & 47,62 \\
\hline 1 & 3 & 14,29 \\
\hline 2 & 2 & 9,52 \\
\hline 3 & 6 & 28,57 \\
\hline Total & 21 & 100,00 \\
\hline \multicolumn{3}{|l|}{ Tempo de experiência } \\
\hline $0-5$ & 9 & 42,86 \\
\hline $6-10$ & 8 & 38,10 \\
\hline 11 a 15 & 3 & 14,29 \\
\hline 16 a 20 & 1 & 4,76 \\
\hline Total & 21 & 100,00 \\
\hline \multicolumn{3}{|l|}{ Padrão das obras } \\
\hline Alto & 25 & 71,43 \\
\hline Médio & 10 & 28,57 \\
\hline Baixo & 0 & 0,00 \\
\hline Total & 35 & 100,00 \\
\hline
\end{tabular}

Fonte: Autores (2018). 
O perfil dos entrevistados constatou que 71,43\% eram engenheiros civis, $14,29 \%$ eram arquitetos, 9,52\% de técnicos em edificações e 4,76\% de auxiliar de engenharia. A proporção de engenheiros por obra identificou $57,14 \%$ responsáveis apenas por uma obra, $23,81 \%$ por duas obras, $14,29 \%$ por três obras e $4,76 \%$ por quatro obras. Valores que indicam que mais de $40 \%$ dos administradores estão encarregados de dois ou mais obras, o que pode influir em uma inadequada supervisão da construção, favorecendo a geração de RCC (Lordsleem \& Pinho, 2015), considerando que 71,43\% dessas obras eram de alto padrão, 28,57\% de médio e nenhuma de baixo padrão.

A rotatividade evidenciou que 47,62\% estão desde o início dos serviços, 14,29\% da administração já foi substituída ao menos uma vez, 9,52\% mudaram duas vezes e $28,57 \%$ com três mudanças no controle das obras. 0 tempo de experiência mostrou que 42,86\% tem até cinco anos de formação, 38,10\% entre seis e dez anos, $14,29 \%$ entre 11 e 15 anos e 4,76\% entre 16 e 20 anos de experiência. Esses valores mostram uma alta rotatividade do pessoal, em torno de $50 \%$ em mais de uma vez, e no caso do tempo de experiência, uma porcentagem em torno de $40 \%$ apenas tem experiência até cinco anos. Paschoalin Filho, Duarte \& Faria (2016) apontam que a baixa qualificação e a rotatividade da mão-de-obra, além da adoção de ferramentas de gerenciamento ineficientes, causam consideráveis volumes de perdas e desperdícios nas construções.

\section{Fontes de desperdício na construção civil}

A Tabela 2 apresenta as dez principais fontes causadoras do desperdício de materiais.

Tabela 2 - Fontes causadoras do desperdício de materiais nas obras

\begin{tabular}{|c|c|c|c|c|c|c|c|c|}
\hline \multirow{2}{*}{ Principais causas dos desperdícios de materiais } & \multicolumn{8}{|c|}{ Frequência (\%) } \\
\hline & \multicolumn{2}{|c|}{0 व 25} & \multicolumn{2}{|c|}{26 a 50} & \multicolumn{2}{|c|}{51 a 75} & \multicolumn{2}{|c|}{$76-100$} \\
\hline 1. Sobreconsumo de materiais & 12 & $57,14 \%$ & 9 & $42,86 \%$ & - & - & - & - \\
\hline 2. Complexidade e alteração de projetos & 6 & $28,57 \%$ & 7 & $33,33 \%$ & 8 & $38,10 \%$ & - & - \\
\hline 3. Processo construtivo envolvido & 5 & $23,81 \%$ & 5 & $23,81 \%$ & 5 & $23,81 \%$ & 6 & $28,57 \%$ \\
\hline 4. Recebimento e guarda dos materiais & 8 & $38,10 \%$ & 13 & $61,90 \%$ & - & - & - & - \\
\hline 5. Retrabalho & 4 & $19,05 \%$ & 7 & $33,33 \%$ & 10 & $47,62 \%$ & - & - \\
\hline 6. Falha nas requisições dos materiais & 7 & $33,33 \%$ & 7 & $33,33 \%$ & 6 & $28,57 \%$ & 1 & $4,76 \%$ \\
\hline 7. Vandalismo e furto & 14 & $66,67 \%$ & 7 & $33,33 \%$ & - & - & - & - \\
\hline $\begin{array}{l}\text { 8. Condições do canteiro onde a obra é } \\
\text { executada }\end{array}$ & 11 & $52,38 \%$ & 10 & $47,62 \%$ & - & - & - & - \\
\hline 9. Movimentação dos materiais no canteiro & 12 & $57,14 \%$ & 8 & $38,10 \%$ & 1 & $4,76 \%$ & - & - \\
\hline 10. Falta de reaproveitamento & 3 & $14,29 \%$ & 6 & $28,57 \%$ & 7 & $33,33 \%$ & 5 & $23,81 \%$ \\
\hline
\end{tabular}

Fonte: Autores (2018).

O sobreconsumo de materiais foi identificado por 12 participantes, representando entre zero e $25 \%$ das causas dos resíduos, enquanto nove deles indicaram uma relevância entre $26 \%$ e $50 \%$. A complexidade e alteração de projetos foi observada por seis, com relevância entre zero e $25 \%$, por sete com $26 \%$ a $50 \%$ e oito com representatividade entre $51 \%$ e $75 \%$. Os processos construtivos envolvidos foram mencionados como causas para os desperdícios em todas as faixas, sendo que seis acreditam que a relevância seja entre $76 \%$ e $100 \%$.

O recebimento e guarda dos materiais foi apontado por oito dos entrevistados com relevância de zero a $25 \%$ e por 13 entre 26 e 50\%. 0 retrabalho foi destacado por quatro respondentes, com grau de importância entre zero e $25 \%$, por sete entre $26 \%$ e $50 \%$, e por dez entre $51 \%$ e $75 \%$. As falhas nos pedidos dos materiais foram apontadas em todos os intervalos, muito embora apenas um dos participantes tenha considerado muito relevante esta causa.

0 vandalismo e o furto foram destacados por 14 respondentes que atribuíram peso entre zero e $25 \%$, enquanto os sete demais o destacaram com percentuais entre $26 \%$ e $50 \%$. As condições do canteiro foram mencionadas por 11 participantes como relevante entre zero e $25 \%$ e os demais atribuíram percentuais entre $26 \%$ e $50 \%$. 0 transporte de materiais obteve 12 escolhas entre zero e $25 \%$, 8 entre $26 \%$ e $50 \%$ e um escolha entre $51 \%$ e $75 \%$. A falta de reaproveitamento mencionadas por todos os entrevistados, tendo como destaque sete deles que atribuíram percentual entre $50 \%$ e $75 \%$.

Os resultados apresentados são semelhantes aos encontrados por Wahab \& Lawal (2011), com a diferença que a maior porcentagem dos participantes indicou que a maior relevância nos desperdícios dos materiais 
fora devido ao dano do material pelas condições ambientais e uma guarda inadequada, seguido do retrabalho e do vandalismo.

\section{Fatores influenciadores dos desperdícios nas obras}

A Tabela 3 mostra os fatores que afetam o desperdício de materiais nos canteiros de obra, tendo como causas a variação dos projetos. Dentre esses fatores, a exigência do cliente alcançou um Índice de Importância Relativa (IIR) de 4,05, sendo este considerado muito relevante a muitíssimo relevante para a geração dos resíduos. A complexidade dos projetos recebeu um índice de 3,95, seguida da modificação dos apartamentos com 3,86 e finalmente a falta de informações nos projetos com 3,52, ficando estes com pontuações de relevante a muito relevante. Na pesquisa realizada por Wahab \& Lawal (2011), também mostra que a solicitação do cliente por mudanças no projeto associado a um projeto complexo tem índices mais elevados, de 3,97 e 3,87 , respectivamente.

Tabela 3 - Índice de Importância Relativa das causas da variação dos projetos

\begin{tabular}{|c|c|c|c|c|c|c|c|c|}
\hline Fatores & MIR (5) & MR (4) & $R(3)$ & PR (2) & NR (1) & SVP & IIR & Posição \\
\hline Exigência do cliente de última hora & 11 & 4 & 3 & 2 & 1 & 85 & 4,05 & 1 \\
\hline Projeto complexo & 9 & 6 & 3 & 2 & 1 & 83 & 3,95 & 2 \\
\hline Apartamento modificado & 7 & 7 & 5 & 1 & 1 & 81 & 3,86 & 3 \\
\hline Falta de informações nos projetos & 6 & 6 & 4 & 3 & 2 & 74 & 3,52 & 4 \\
\hline Falta de detalhamento construtivo & 5 & 3 & 4 & 3 & 6 & 61 & 2,90 & 5 \\
\hline Condições de solo imprevistas & 3 & 3 & 5 & 4 & 6 & 56 & 2,67 & 6 \\
\hline Longa duração do projeto & 1 & 3 & 3 & 6 & 8 & 46 & 2,19 & 7 \\
\hline
\end{tabular}

Fonte: Autores (2018). Nota: MIR= muitíssimo relevante, $M R=$ muito relevante, $R=$ relevante, $P R=$ pouco relevante, $N R=n a ̃ o$ relevante, $S V P=$ soma do valor de peso e $\| R=$ índice de importância relativa.

Quanto ao critério de seleção dos materiais, a Tabela 4 mostra que o custo da aquisição dos materiais recebeu um índice de 4,24, ficando entre muitíssimo relevante a muito relevante. Disponibilidade do material no mercado recebeu pontuação igual a 4,00, sendo um item considerado muito relevante para a produção dos RCC, pois é comum o mercado disponibilizar determinados materiais em medidas padrões, ocasionando uma perda originada antes mesmo do material ser utilizado. A exigência de projetistas e clientes, além dos locais aptos para recebimento e estocagem dos materiais, receberam respectivamente 3,95 e 3,62 pontos. Wahab \& Lawal (2011) e Poon et al. (2001) identificaram como os fatores mais relevantes o custo, facilidade de construção, requerimentos do cliente e disponibilidade dos materiais no mercado.

Tabela 4 - Índice de Importância Relativa das causas para seleção dos materiais

\begin{tabular}{|c|c|c|c|c|c|c|c|c|}
\hline Fatores & MIR (5) & MR (4) & $R(3)$ & PR (2) & NR (1) & SVP & IIR & Posição \\
\hline Custo de aquisição & 12 & 5 & 2 & 1 & 1 & 89 & 4,24 & 1 \\
\hline Disponibilidade no mercado & 10 & 5 & 3 & 2 & 1 & 84 & 4,00 & 2 \\
\hline Exigência de projetistas e clientes & 8 & 7 & 4 & 1 & 1 & 83 & 3,95 & 3 \\
\hline Locais de recebimento e estocagem & 7 & 6 & 3 & 3 & 2 & 76 & 3,62 & 4 \\
\hline Forma do pedido & 5 & 3 & 4 & 3 & 6 & 61 & 2,90 & 5 \\
\hline Dimensões ou embalagens & 3 & 3 & 6 & 4 & 5 & 58 & 2,76 & 6 \\
\hline Pré-disponibilidade para produção de resíduos & 1 & 2 & 4 & 7 & 7 & 46 & 2,19 & 7 \\
\hline
\end{tabular}

Fonte: Autores (2018). Nota: MIR= muitíssimo relevante, $M R=$ muito relevante, $R=$ relevante, $P R=$ pouco relevante, $N R=$ não relevante, $S V P=$ soma do valor de peso e $\| R=$ índice de importância relativa.

A Tabela 5 apresenta o IIR das causas do desperdício dos materiais a partir da escolha de determinados métodos construtivos. Neste sentido o custo da construção recebeu 4,14 pontos, superando alguns fatores intrínsecos da própria construção. Acredita-se que quanto menor o custo para a realização de uma obra, existirá menos controle da gestão dos resíduos, sobretudo devido à falta de profissionais ligados à área de meio ambiente, e uma menor cultura voltada para a reutilização dos materiais. 
Análise dos fatores de influência e diagnóstico da gestão dos resíduos da construção civil (RCC) nos canteiros de obra da cidade do Recife-PE

Tabela 5 - Índice de Importância Relativa das causas para seleção métodos construtivos

\begin{tabular}{|c|c|c|c|c|c|c|c|c|}
\hline Fatores & MIR (5) & MR (4) & $R(3)$ & PR (2) & NR (1) & SVP & IIR & Posição \\
\hline Custo da construção & 10 & $\frac{7}{7}$ & 2 & 1 & 1 & 87 & 4,14 & 1 \\
\hline Tipo da fundação & 9 & 5 & 3 & 3 & 1 & 81 & 3,86 & 2 \\
\hline Tipo do elemento de vedação & 8 & 7 & 2 & 2 & 2 & 80 & 3,81 & 3 \\
\hline $\begin{array}{l}\text { Tipo do revestimento interno e } \\
\text { externo }\end{array}$ & 7 & 7 & 2 & 3 & 2 & 77 & 3,67 & 4 \\
\hline Tipo da estrutura & 5 & 3 & 4 & 3 & 6 & 61 & 2,90 & 5 \\
\hline Escavação de subsolo & 3 & 3 & 5 & 4 & 6 & 56 & 2,67 & 6 \\
\hline $\begin{array}{c}\text { Familiaridade com a tecnologia } \\
\text { adotada }\end{array}$ & 2 & 2 & 3 & 6 & 8 & 47 & 2,24 & 7 \\
\hline
\end{tabular}

Fonte: Autores (2018). Nota: $M I R=$ muitíssimo relevante, $M R=$ muito relevante, $R=$ relevante, $P R=$ pouco relevante, $N R=$ não relevante, $S V P=$ soma do valor de peso e $\| \mathbb{R}=$ índice de importância relativa.

O tipo de fundação recebeu 3,86 pontos, seguidos da escolha do elemento de vedação com 3,81 de IIR, e do tipo de revestimento externo e interno com 3,67 pontos, todos esses dentro do critério de classificação entre relevante e muito relevante. Os demais receberam pontuação inferior a três, sendo considerados de pouco relevante a relevante, com destaque para a familiaridade do método construtivo que recebeu 2,24 foi classificado como "não relevante" para a geração dos RCC. Na pesquisa de Wahab \& Lawal (2011) também o custo da construção tem a maior relevância com 3,86; no entanto, fatores como de tempo de construção e requerimentos do construtor são considerados como relevantes. Poon, Yu \& Ng (2001) identificaram fatores mais relevantes, como o tempo de construção, custo de construção e familiaridade com a tecnologia de construção.

\section{Gestão dos resíduos nos canteiros de obra do Recife - PE}

A Tabela 6 apresenta o resumo de 15 obras onde foi realizado um diagnóstico da geração dos RCC, com o resumo de suas principais informações, tais como: Área construída, duração, no de pavimentos, geração de resíduos, fase de construção e se possui alguma certificação.

Tabela 6 - Caracterização dos canteiros com diagnostico da gestão dos RCC

\begin{tabular}{ccccccc}
\hline Obra & $\begin{array}{c}\text { Área construída } \\
\left(\mathbf{m}^{\mathbf{2}}\right)\end{array}$ & $\begin{array}{c}\text { Duração } \\
(\mathbf{m e s e s})\end{array}$ & $\begin{array}{c}\text { Número de } \\
\text { pavimentos }\end{array}$ & $\begin{array}{c}\text { Peso do resíduo } \\
(\mathbf{k g})\end{array}$ & $\begin{array}{c}\text { Fase atual da } \\
\text { obra }\end{array}$ & $\begin{array}{c}\text { Possui } \\
\text { certificação? }\end{array}$ \\
\hline 1 & 6031,02 & 31 & 14 & 434932 & Acabamento & Sim \\
2 & 6127,20 & 25 & 22 & 492780 & Acabamento & Não \\
3 & 6861,11 & 28 & 18 & 3114542 & Acabamento & Sim \\
4 & 7059,72 & 22 & 20 & 21915 & Acabamento & Sim \\
5 & 7733,85 & 30 & 25 & 1091360 & Acabamento & Sim \\
6 & 8140,57 & 27 & 23 & - & Estrutura & Não \\
7 & 8318,42 & 25 & 14 & 597655 & Acabamento & Sim \\
8 & 9460,83 & 27 & 23 & 442266 & Acabamento & Não \\
9 & 10728,00 & 31 & 28 & 16439 & Estrutura & Não \\
10 & 11667,16 & 52 & 33 & 525566 & Acabamento & Não \\
11 & 12554,54 & 50 & 30 & 615708 & Acabamento & Não \\
12 & 15206,91 & 28 & 44 & 642720 & Acabamento & Sim \\
13 & 16098,68 & 38 & 15 & 316297 & Acabamento & Sim \\
14 & 17614,10 & 34 & 33 & 645853 & Acabamento & Sim \\
15 & 17645,67 & 33 & 20 & 22251 & Estrutura & Não \\
\hline
\end{tabular}

Fonte: Autores (2018).

Das 15 obras pesquisadas, oito possuem certificação ISO 14001, e sete delas são obras de construtoras não certificadas. Contudo, a forma de controle e caracterização dos resíduos nas obras certificadas é mais eficaz do que nas outras. A preocupação com a gestão dos resíduos vai desde a sua geração até o seu destino. 


\section{Triagem ou segregação na fonte}

Conforme a resolução 307/2002 (CONAMA, 2002) no art. 3ํa a triagem ou segregação deverá ser realizada de preferência na origem pelo gerador do resíduo, ou ser realizada em áreas apropriadas de destinação autorizadas com esta finalidade. Para tal, devem ser formadas pilhas próximas aos locais que serão transportados os materiais que serão segregados, e em seguida realiza-se o seu acondicionamento.

Ao fim de um dia de atividade ou ao término de um determinado serviço, pôde ser observado que seis das quinze obras realizavam a segregação dos resíduos. Esta prática evitou que os resíduos se acumulassem e se misturassem a outros de diversas classes conforme também apontado por Paz (2014). É importante assegurar que o RCC esteja isento de materiais contaminantes, potencializando desse modo a sua reutilização ou reciclagem.

Esta conduta contribuiu ainda para a segurança e limpeza da obra, evitando que os materiais e as ferramentas ficassem espalhados pelo canteiro de obra, gerando contaminação entre os resíduos e desorganização, aumentando desse modo a possibilidade da ocorrência de acidentes, além de acréscimo na geração dos resíduos nas obras.

Apesar do empenho em segregar os materiais, foi possível observar muito resíduo misturado em caçambas coletoras e baias de segregação. As caçambas localizadas fora do canteiro possibilitaram que qualquer gerador depositasse o seu resíduo, ocasionado um percentual elevado de mistura, impossibilitando o seu reaproveitamento. Os equipamentos de proteção individual (EPI), em algumas empresas foram classificados como resíduos perigosos e seguiram para incineração.

\section{Acondicionamento}

Após a segregação na fonte, os RCC foram armazenados em recipientes posicionados e distribuídos ao longo da obra: bombonas, caixas de coleta, bags ou caçambas, até atingirem volumes suficientes que justificassem o seu transporte interno para o depósito, de onde saíram para serem reutilizados, reciclados ou destinos de modo adequado. Os resíduos foram acondicionados em dispositivos instalados com sinalização de acordo com a classe do RCC.

Todas as obras pesquisadas realizam o acondicionamento dos RCC, esta prática facilita a retirada dos resíduos das obras. Essa forma de armazenamento possibilitou que os resíduos de construção continuassem segregados. Os materiais mais leves como os plásticos, embalagens de papel de cimento e argamassas, foram colocados em bags; materiais classe A ou B, tais como: areias, argamassa e gesso, foram acondicionados em caçambas metálicas.

\section{Transporte interno e externo}

O transporte externo, ou seja, aquele que ocorre entre o canteiro de obras e a central de destinação, seja ela usina de reciclagem ou aterro sanitário, é feito por empresa especializada, devidamente credenciada na Empresa de Manutenção e Limpeza Urbana (EMLURB). 0 uso de GPS nas unidades transportadoras é de uso obrigatório, pois evita o despejo irregular dos RCC em logradouros públicos.

O transporte interno dos RCC em todas as obras é realizado por carrinhos de mão, elevadores de carga, guinchos, gruas ou manipuladores telescópicos. 0 operador do guincho aproveita as descidas vazias do equipamento para transportar os recipientes dos RCC até o local do depósito final, conforme sua classificação. Algumas obras pesquisadas preferem transportar os resíduos misturados (sem segregação na fonte), e realizar a sua separação em um local específico.

\section{Disposição final dos RCC}

A destinação final dos RCC é feita de acordo com o tipo de resíduo. Os RCC classe A são encaminhados para centrais de reciclagem de agregados em cinco das 15 obras, os resíduos classe B são enviados para 
cooperativas e associações de catadores em dois das 15 obras, os resíduos classe C, em todas as obras seguem para os aterros sanitários mais próximos, dentre eles, o Central de Tratamento de Resíduos (CTR) Candeias, CTR Igarassu e CTR Pernambuco, assim como os resíduos classe D que vão para incineração.

Além da análise da gestão, também foi possível identificar os fatores que dificultaram a obtenção de dados de RCC, tanto de geração de resíduos quanto de sua caracterização, conforme Quadro 1.

Quadro 1 - Dificuldades encontradas para coleta de dados em 15 obras

- $\quad$ Elevada rotatividade da administração da obra;

- $\quad$ Falta de controle e organização dos documentos;

- Vinculação da gestão de resíduos de mais de uma torre em canteiros únicos;

- Dados em fichas amassadas e rasuradas;

- Dados não compilados em planilhas eletrônicas;

- Parceiros de coleta não cadastrados na EMLURB

- $\quad$ Falta de mão-de-obra específica para gerenciamento e controle dos resíduos;

- Falta de segregação e classificação dos resíduos gerados;

- Gestão de resíduos tratada como atividade secundária e pouco relevante para o resultado do empreendimento;

- Inobservância no cumprimento dos requisitos da ISO 14001;

- Obras paralisadas durante a pesquisa;

- Desinteresse em passar determinadas informações.

Fonte: Autores (2018).

\section{Considerações finais}

A análise do perfil da administração de 35 obras possibilitou identificar que a maioria dos responsáveis eram engenheiros civis, seguido por arquitetos, técnicos de edificações e auxiliares de engenharia. A proporção de administrador por obra revelou que mais de $40 \%$ desses funcionários ficam responsáveis por mais de uma obra e que em mais de $50 \%$ das obras analisadas teve substituição da sua administração, sendo esses dois pontos tema de preocupação.

As fontes causadoras dos desperdícios que mais foram citadas nas entrevistas foram o consumo além do previsto de materiais, a excessiva alteração dos projetos no decorrer das obras e o processo construtivo envolvido. Os fatores que mais influenciaram essa perda de materiais foram a exigência do cliente de última hora quanto há alguma mudança, a complexidade dos projetos e a constante modificação de apartamentos.

Os baixos custos dos materiais como critério de escolha foram apontados por alguns administradores das obras, junto com a disponibilidade de alguns materiais no mercado, sobretudo a madeira o aço e o concreto que são entregues em quantidades e dimensões padrões. Além das exigências de projetistas ou clientes para determinados tipos de materiais e sistemas construtivos. Quanto ao método de construção, o custo foi destacado como o primeiro fator, seguido pela tipologia construtiva da fundação e dos elementos de vedação dos ambientes.

O diagnóstico da gestão dos RCC revelou que as empresas certificadas com a ISO 14001 têm mais eficácia nos métodos de controle dos resíduos do que as construtoras não certificadas. Algumas empresas dispõem de um gestor ambiental que fica responsável por esse gerenciamento, orientando os funcionários quanto à melhor forma de segregação, acondicionamento e transporte dos resíduos nos canteiros.

Pode-se observar que a quantidade de materiais consumidos, bem como os resíduos gerados nos canteiros de obras, é desconhecida pelas próprias empresas, gerando impactos ambientais negativos e condicionando a sobrevivência econômica das empresas. Uma correta identificação e avaliação dos fatores de influência, juntamente com um diagnóstico da geração de resíduos, pode gerar impactos positivos para o meio ambiente como empreendimentos de sucesso.

\section{Referências}

Albuquerque, D. M. S. de. (2015). Impacto socioambiental da deposição irregular dos Resíduos da Construção e Demolição na cidade do Recife-PE (Dissertação de mestrado). Escola Politécnica de Pernambuco, Universidade de Pernambuco, Recife. 
Bohnenberger, J. C., Pimenta, J. F. de P., Abreu, M. V. S., Comini, U. B., Calijuri, M. L., Moraes, A. P. De, Pereira, I. da S. (2018). Identificação de áreas para implantação de usina de reciclagem de resíduos da construção e demolição com uso de análise multicritério. Ambiente Construído, 18(1), pp. 299-311. doi: http://dx.doi.org/10.1590/s167886212018000100222

Câmara Brasileira da Indústria da Construção - CBIC. (2019). Construção é responsável por mais de 50\% dos investimentos no País. 20 de fevereiro de 2019. Recuperado em 14 de abril de 2019, de https://cbic.org.br/construcaoe-responsavel-por-mais-de-50-dos-investimentos-no-pais/

Conselho Nacional do Meio Ambiente - CONAMA. (2002). Resolução no 307, de 5 de julho de 2002. Brasília.

Costa, R. V. G. da, Athayde Júnior, G. B., Oliveira, M. M. de. (2014). Taxa de geração de resíduos da construção civil em edificações na cidade de João Pessoa. Ambiente Construído, 14(1), 127-137. doi: http://dx.doi.org/10.1590/S167886212014000100011

Fernandes, M. da P. M., Silva Filho, L. C. P. da. (2017). Um modelo orientativo para a gestão municipal dos RCCs. Ambiente Construído, 17(2), 21-38. doi: http://dx.doi.org/10.1590/s1678-86212017000200144

Instituto Brasileiro de Geografia e Estatística - IBGE. (2017a). Base de dados por municípios das Regiões Geográficas Imediatas e Intermediárias do Brasil. Rio de Janeiro: IBGE. Recuperado em 14 de abril de 2019, de www.ibge.gov.br. Instituto Brasileiro de Geografia e Estatística - IBGE. (2017b). População estimada. 2017. Rio de Janeiro: IBGE. Recuperado em 14 de abril de 2019, de www.ibge.gov.br.

Li-Yashuai. (2013). Developing a Sustainable Construction Waste Estimation and Management System. (Thesis) Hong Kong University of Science and Technology, Hong Kong. doi: 10.14711/thesis-b1226942

Lordsleem, A. C., Pinho, S. A. (2015). Medição de desperdícios na construção de edifícios (1a ed., Vol. 1). Recife: Universidade de Pernambuco.

Magalhães, R. F., Danilevicz, A. M. F, Saurin, T. A. (2017). Reducing construction waste: A study of urban infrastructure projects. Waste Management, 67, 265-277. doi: http://dx.doi.org/10.1016/j.wasman.2017.05.025

Mália, M., Brito, J., Pinheiro, M., Bravo, M. (2013). Construction and demolition waste indicators. Waste Management \& Research, 31(3), 241-255. doi: http://dx.doi.org/10.1177/0734242X12471707

Marques, O. B., Oliveira, R. M. S., Picanço, A. P. (2013). Resíduos de construção civil: geração e alternativas para reciclagem em um canteiro de obras de pequeno porte. Engenharia Ambiental - Espírito Santo do Pinhal, 10(2), 143156.

Melo, A. V. S., Ferreira, E. de A. M., Costa, D. B. (2013). Fatores críticos para a produção de agregado reciclado em usinas de reciclagem de RCC da região nordeste do Brasil. Ambiente Construído, 13(3), 99-115. doi: http://dx.doi.org/10.1590/S1678-86212013000300007

Mendoza, F. J. C., Altabella, J. E., Izquierdo, A. G. (2016). Application of inert wastes in the construction, operation and closure of landfills: Calculation tool. Espanha: Waste Management, Mechanical Engineering and Construction, Universidad Jaume I.

Mesquita, A. S. G. (2012). Análise da geração de resíduos sólidos da construção civil em Teresina, Piauí. Revista Holos, 2 , 58-65. doi: https://doi.org/10.15628/holos.2012.835

Monteiro, H. F. M. S. (2012). Resíduos de construção e Demolição (Estado da Arte) (Dissertação de mestrado). Faculdade de Ciências da Universidade do Porto, Porto.

Paschoalin Filho, J. A., Duarte, E. B. de L., Faria, A. C. (2016). Geração e manejo dos resíduos de construção civil nas obras de edifício comercial na cidade de São Paulo. Revista Espacios, 37(6) 30.

Paz, D. H. F. (2014). Desenvolvimento de um sistema de apoio ao gerenciamento de resíduos sólidos da construção civil em canteiros de obras de edificações urbanas (Dissertação de mestrado). Escola Politécnica de Pernambuco, Universidade de Pernambuco, Recife.

Paz, D. H. F., Lafayette, K. P. V. (2016). Forecasting of construction and demolition waste in Brazil. Waste Management \& Research, 34(8), 708-716. doi: https://doi.org/10.1177/0734242X16644680 
Análise dos fatores de influência e diagnóstico da gestão dos resíduos da

construção civil (RCC) nos canteiros de obra da cidade do Recife-PE

Pinho, S. A. C. (2013). Desenvolvimento de programa de indicadores de desempenho para tecnologias construtivas à base de cimento: perdas, consumo e produtividade (Dissertação de mestrado). Escola Politécnica de Pernambuco, Universidade de Pernambuco, Recife.

Poon; C. S., Yu, A. T. W., Ng, L. H. (2001). A guide for managing and minimizing building and demolition waste. Hong Kong: Dept. of Civil \& Structural Engineering, Hong Kong Polytechnic University.

Recife - Prefeitura de Recife. (1997). Lei municipal nº 16.293, de 22 de janeiro de 1997. Recife.

Santos, D. S. dos. (2015). Diagnóstico da Gestão dos Resíduos de Construção e Demolição e seus Impactos Ambientais no Município de Jaboatão dos Guararapes/PE (Dissertação de mestrado). Escola Politécnica de Pernambuco, Universidade de Pernambuco, Recife.

Santos, P. R., Santos, D. de G. (2017). Investigação de perdas devido ao trabalho inacabado e o seu impacto no tempo de ciclo dos processos construtivos. Ambiente construído, 17(2), 39-52. doi: http://dx.doi.org/10.1590/s1678-

86212017000200145

Silva, N. M. da, Ishida, H. Y., Lukiantchuki, J. A., Reis, J. H. C. dos, Silva, C. F. da. (2018). Quebra do grão em Resíduos de Construção Civil (RCC) induzida pelo processo de compactação. Ambiente Construído, 18(1), 281-298. doi: http://dx.doi.org/10.1590/s1678-86212018000100221

Souza, U. B. L., Paliari, J. C., Andrade, A. C., Agopyan, V. (1998). Perdas de materiais nos canteiros de obras: a quebra do mito. Qualidade na Construção, 2(13), 1-11.

Viana, D. D., Formoso, C. F., Kalsaas, B. T. (2012). Waste in construction: a systematic literature review on empirical studies. In Annual Conference of the International group for Lean Construction. San Diego: State University of San Diego.

Wahab, A. B.; LawaL, A. F. (2011). An evaluation of waste control measures in construction industry in Nigeria. African Journal of Environmental Science and Technology, 5(3), 246-254.

Wu, Z., Yu, A. T. W., Shen, L. (2017). Investigating the determinants of contractor's construction and demolition waste management behavior in Mainland China. Waste Management, 60, 290-300. doi: https://doi.org/10.1016/j.wasman.2016.09.001

Editor: Harry Bollmann.

Recebido: Abr. 21, 2019

Aprovado: Maio 24, 2019 